\title{
NOTAS
}

\section{ESPAÑA Y LA "DISPUTA DE ANTIGUOS Y MODERNOS"}

España vivió apasionadamente su propia versión de la querella entre antiguos y modernos en su reacción a las Soledades de Góngora y al teatro de Lope, y se anticipó a los más sonados argumentos de la famosa querelle francesa: proclama la superioridad imaginativa y artística de los modernos, su derecho de innovar y su buen gusto.

Las disputas italianas del siglo $\mathbf{x v} \mathbf{I}$ son las que por primera vez plantean, dentro de la historia crítica moderna, la cuestión de la legitimidad de las innovaciones. Cuestión que los italianos resolvieron con "temor" y "cobardía", como decía un español de la época". España, quizá por tradición que antepone religión verdadera a letras profanas, siempre profesó libertad crítica en éstas, pues el admirar a los antiguos no impedía contradecir sus cánones literarios.

Huarte de San Juan (1575) y Fernando de Herrera (1580), dando nuevo impulso a la noción de que los modernos superan a los antiguos, inspiran directamente a los polemistas españoles del siglo xvn. Huarte concibe el progreso como una pirámide infinita en que el presente empuja sus esfuerzos hacia la cumbre de lo perfecto apoyándose en lo válido de la tradición. La aparición de nuevos ingenios inventivos es, pues, indispensable para asegurar la continuidad de una secular tradición: "...el orden y concierto que se ha de tener para que las ciencias resciban cada día aumento y mayor perfección es juntar la nueva invención de los que ahora vivimos con lo que los antiguos dejaron escrito en sus libros; porque haciéndolo de esta manera cada

1 "Grande ingenio prometen de sus autores el Pastor Fido y el Aminta: grande y digno de admiración, pero temeroso y acobardado. No tuvieron ánimo para sacudir el yugo de la antigüedad", palabras de Francisco de la Barreda, Panegírico de Plinio a Trajano (1622), en Menéndez Pelayo, Historia de las ideas estéticas en España, Madrid, 1962, t. 2, p. 319. Bernard WeINBerg, A history of literary criticism in the Italian Renaissance, Chicago, 1961, t. 2, passim, ha mostrado que las querellas sobre Dante, Ariosto y Tasso, Speroni y Guarini, que abarcan todo el siglo, se desarrollaron dentro del estricto marco aristotélico, al cual se atienen aun aquellos que defienden la superioridad moderna. España, en cambio, muy temprano se desprendió de la autoridad de las preceptivas clásicas. Ya a principios del siglo xv Alonso de Cartagena, eclesiástico y converso, aconsejaba a los lectores de su traducción de la Retórica de Cicerón que cada quien observara sólo aquellas reglas que mejor le conviniera: "cada uno saque por su ingenio aquello que entendiere que pára en lo que quiere fablar" (cit. por Gallardo, Ensayo, t. 2, col. 263). $\mathrm{Y}$ en 1539 , CRISTóbal de Villalón componía la Ingeniosa comparación entre lo antiguo y lo presente, en que se defiende la idea del proceso civilizador de los siglos (véase M. Bataillon, Erasmo y España, México, 1950, t. 2, pp. 264-265). 
uno en su tiempo, vernían a crecer las artes, y los hombres que están por nascer gozarían de la invención y trabajo de los que primero vinieron" $"$. Contrastando así antiguos y modernos, concluye que el presente importa más que el pasado: sabemos más cada día. No es menos cálido el alegato de Herrera en favor de los modernos. Una frase suya resume la corriente de independencia que anima las Anotaciones a Garcilaso: la admiración servil a los escritores antiguos es "religión supersticiosa", porque ellos "ombres fueron como nosotros, cuios sentidos $\mathrm{i}$ juicios padecen engaño i flaqueza, i así pudieron errar i erraron"' 3

Con argumentos análogos, los impugnadores franceses de la autoridad antigua reafirmarán una y otra vez el mérito de la experiencia y lo falible de los modelos clásicos. Los modernos son superiores porque "ils ont profité du travail et de l'étude de ceux qui les ont précédés", o bien: "Ils [los antiguos] sont grands, il est vrai, mais hommes comme nous" ". Sabemos más hoy porque heredamos "les richesses et les dépouilles cle tous les siècles passés, et le pouvoir de juger et de profiter de toutes les inventions, de toutes les expériences et de toutes les fautes des autres" 5 . Se critica la veneración a la antigüedad clásica: "[On ne considère pas qu']Aristote, Platon, Epicure étaient hommes comme nous... et de plus, [qu']au temps où nous sommes, le monde est plus âgé de deux mille ans, [qu']il a plus d'expérience, [qu']il doit être plus éclairé, et [que] c'est la vieillesse du monde et l'expérience qui font découvrir la vérité". Sólo para igualar a los antiguos, "il faudrait que nous fussions d'une nature fort inférieure à la leur, il faudrait presque que nous ne fussions pas hommes aussi bien qu'eux"' Parece evidente la semejanza entre este modo de argumentación, núcleo de la Querelle des Anciens et des Modernes, y el que hemos visto en los escritores españoles.

Éstos conceden a los poetas el privilegio de innovar, como derecho suyo indiscutible, pero las novedades deben además satisfacer el gusto de los lectores y el de los críticos. Lope recibe el apoyo de las mayorías, y las discusiones sobre el teatro son por tanto lo bastante apaci-

2 Examen de ingenios para las ciencias, ed. R. Sanz, Madrid 1930, t. 1, p. 146. No basta la sola conservación de lo antiguo: "conviene que haya en las letras humanas algunos ingenios caprichosos que descubran a los entendimientos oviles nuevos secretos de naturaleza y les den contemplaciones, nunca oídas, en que ejercitarse. Porque desta manera van cresciendo las artes, y los hombres saben más cada dia" (ibid.).

3 Véase A. Viranova, "Preceptistas españoles de los siglos xvı y xvn", en Historia general de las literaturas hispinicas, Barcelona, 1953, t. 3, p. $5^{81}$. Nótese también que Fierrera se vale de una autoridad clásica, la de Quintiliano, para poner en duda la infalibilidad de los clásicos: "Neque id statim legenti persuasum sit, omnia quae optimi auctores dixerint utique esse perfecta... nonnumquam fatigantur, cum Ciceroni dormitare interim Demosthenes, Horatio vero etiam Homerus ipse videatur. Summi enim sunt, homines tamen..." (Inst. oratoriae, X, 1).

1 Ch. Perrault, Critique de l'Opera... (1674), apud A. Hallays, Les Perrault, Paxis, 1006 . P. 148

5 Desmarets de Saint-Sorlin, Traité pour juger les poètes grecs, latins et francais $(1670)$, apud Hallays, pp. 142-149.

6 Malebranche, Recherche de la vérité (1647), Paris, 1962, t. 1, p. 150.

7 Fontener.r., Digression sur les anciens et les modernes (1688), Oxford, 1955, p. 166. 
bles para permitir la exposición y defensa de la nueva orientación dramática. No así en el caso de Góngora, cuya reñida recepción en las letras oscurece los puntos litigiosos de la contienda. Con todo, el relativismo implícito en la noción del gusto determina el tono de toda la crítica española del xvn, y el que lo invocaran tantos críticos en la defensa del teatro y en la polémica gongorina prueba la vitalidad del concepto de "buen gusto" en el primer tercio del siglo.

Gusto y buen gusto son términos que penetraron en el léxico crítico antes de las grandes disputas del siglo xvu, como, por ejemplo, cuando fray José de Sigüenza (16oo) recomienda la lectura del Lazarillo, libro "que merece ser leydo de los que tienen buen gusto"8. Pero se generalizan a raiz de las Soledades y del éxito de Lope en frases que muestran la importancia del auditorio. Ricardo de Turia (1616) habla de un "gusto español" ya formado en la lectura de un teatro libre de restricciones en cuanto a género y a unidades de acción, tiempo y lugar, y elogia la nueva comedia a base de una "constante máxima", la de "satisfacer el gusto para quien escriben" los poetas". Apenas hace falta recordar la socarronería de Lope al declarar que se dirige al vulgo y que, por tanto, escribe "en necio", "para darle gusto"10. Góngora, en cambio, busca complacer el gusto de la docta minoría, pero aun en ésta hay tantos gustos como individuos y a ello se debe la controversia sobre su estilo, según uno de sus apologistas: "Suele la novedad causar esta contradiçión por ser en la materia de el modo de deçir, en que cada uno, según su ingenio, gusta de diferente estylo"11. Tan relativo es el gusto, que Jáuregui (1623) se siente llamado a definirlo: "Así que para entender ilustres versos, supongo por oyentes a lo menos buenos juicios y alentados ingenios cortesanos de suficiente noticia y buen gusto, y sobre todo inclinados al arte", y "hay hombres de tan claro ingenio y tanta viveza en el gusto, aunque sin estudios, que guiados sólo de su natural, aciertan a agradarse más

s Historia de la orden de San Gerónimo, t. 12 de la NBAE, p. $145 b$.

9 "Pues si esto es asf́, y estas comedias no se han de representar en Grecia ni en Italia, sino en España, y el gusto español es deste metal, ¿por qué ha de dexar el poeta de conseguir su fin, que es el aplauso... por seguir las leyes de los pasados?" (Apologético de las comedias españolas, cit. por Menéndez Pledyo, op. cit., t. 2, pp. 309-310. Véanse también las pp. 275-324 para más ejemplos del uso de la frase buen gusto en textos relativos al teatro).

10 Arte nuevo de hacer comedias, en Obras escogidas. Poesia y prosa, Madrid, 1953, p. 887.-A. Alatorre me llama la atención sobre un pasaje en que Lope vuelve a la idea de Herrera para protestar contra el culto excesivo a los grandes difuntos a expensas de la admiración que se debe a los vivos: "Notables palabras de aquel filósofo contra los que piensan que no se puede alabar ni estimar lo que habemos conocido y tratado, y que sólo es digno de fama lo que no vimos ni conocimos... jDesdicha humana, remitir precisamente la fama para el sepulcro, donde, callando la lengua, hablen los mármoles, y que lo que se merece en vida se reserve para la muerte, cuando el que no vio ni conoció al que escribe (y que él tenga tan poco que le agradecer como quien ya no siente) haga tan diferente idea de su rostroł... ¿Por qué no gozará de la fama en vida quien la merece mucrto?... ¿Qué objeción puede ser haber nacido en este siglo...?" (El cardenal de Belén, Acad, t. 5, p. 153).

11 Dfaz dE Rivas, Discursos apologéticos (ca. 1618), apud E. J. Gatrs, Documentos gongorinos, México, 1960, p. 22. 
de la mejor poesía y menos de la inferior, bien que no averiguan razones desta ventaja ni saben los medios por donde se adquiere" 12 . Un curioso anónimo había reprobado precisamente a Jáuregui su encono contra Góngora en el Antidoto, escrito antes de 1618, echándole en cara sobre todo que, "siendo $V m$. español y andaluz, aya querido escurecer lo que tantos doctos españoles, y hombres de buen gusto, an alabado..." 13 Nadie rindió tan generoso culto teórico al gusto como Gracián, que llegó hasta elevarlo a categoría de "ciencia": "Hállanse unos hombres apreciadores de todo sazonado dicho y observadores de todo galante hecho... Éstos son los oráculos de la curiosidad y maestros desta ciencia del buen gusto" ${ }^{14}$. Resultaría tedioso enumerar más ejemplos.

E. B. O. Borgerhoff ha estudiado el papel del gusto y del je ne sais quoi en Francia, es decir, el papel de la critica sentimental antes que Boileau impusiese sobre estas nociones los principios de universalidad absoluta que legó al siglo xvıı. Cita, como ejemplo más temprano, a Guez de Balzac (1645), quien escribía a un corresponsal: "Puisque vous goûtez mes derniers Ecrits, et que vous avez le goût extrêmement bon..." 15 Y René Wellek, en su History of modern criticism (New Haven, 1955), ha señalado la importancia de la noción del buen gusto, que representa "the crystallizing point of the new concepts that turned attention to the individual state of mind of the reader or listener" (t. 1, p. 14). No es, dice Wellek, invención española. Cita la frase de Guez de Balzac que aduce Borgerhoff, y alude a un pasaje anterior de Ludovico Zuccolo (1629) que define el buen gusto como "una certa potenza superiore, unita insieme con l'occhio e con l'orecchio, forma un cotai giudicio: la qual potenza tanto meglio conosce, quanto più d'acutezza nativa o più di perizia nell'arte, senza però valersi di discorso". A base de estos ejemplos, Wellek concluye que "the widely held view that 'taste' comes from Spaim and particularly from Baltazar Gracián is thus untenable" (p. 24). Con lo cual combina, para rechazarlas mejor, dos afirmaciones de muy distinto alcance, que convendría distinguir cuidadosamente.

Los españoles llevan la defensa de la invención más lejos que sus predecesores italianos. No sólo rechazan el principio de imitación

i2 Discurso poético, texto íntegro en J. JoRDín de URRíes, Biografía y estudio crítico de Jáuregui, Madrid, 1899, pp. 225, 255.

13 Opúsculo inédito contra el "Antidoto" de Jáuregui, en ArTigas, Don Luis de Góngora, Madrid, 1925, p. 395 .

14 El discreto $(1646)$, en sus Obras completas, Madrid, 1960, p. go.

15 E. B. O. Borgerhoff, The freedom of French classicism, Princeton, 1950, p. 14. Recuérdese que Juan de Valdés destaca el giro "no sé qué" de cierta copla española porque "tiene gracia, y muchas vezes se dize a tiempo que significa mucho", mientras que, más adelante, la aplica negativamente y por su propia cuenta a la crítica de las canciones: "De las canciones me satisfazen pocas, porque en muchas veo un no sé qué dezir baxo y plebeyo" (Diálogo de la lengua, Madrid, 1928, pp. 148, 163). El "no sé qué" aparece reiteradamente a lo largo del xvı español, en prosa y en verso (y maravillosamente en el Cántico espiritual). Veo ahora que el Prof. Porqueras Mayo leyó un trabajo sobre el "no sé qué" en el II Congreso Internacional de Hispanistas (Nimega, I965). 
característico de las preceptivas antiguas; discuten también la idea del poeta-artífice frente al poeta-profeta. El tópico del "inventor" y la justificación de las mudanzas en el arte por razones de uso y costumbres arraigan en Italia, donde se generalizan a lo largo de las controversias del Cinquecento. Tirso de Molina intenta explicar los empeños modernos con razonamientos válidos para el teatro y la lírica, especialmente la lírica de Góngora, y sus argumentos procuran penetrar -más allá de los alegatos anteriores- en la esencia de las transformaciones artísticas. Su idea del poeta es, en efecto, la de un sutil artífice que combina, buscando armonizarlos, los elementos contradictorios de la naturaleza. Llama "mezcla apacible destos encontrados poemas" a lo tragicómico de la nueva comedia, aplicando así a un caso particular (la comedia) una ley más general que abarca todas las artes y que las opone a la naturaleza. La naturaleza se ofrece en su inmensa diversidad como materia bruta, no para ser imitada (copiada), sino para que el poeta-artífice, escogiendo sus "injertos", recree con gran industria algo infinitamente más hermoso:

Esta diferencia hay de la naturaleza al arte: que lo que aquélla desde su creación constituyó no se puede variar; y así siempre el peral producirá peras y la encina su grosero fruto... Fuera de que, ya que no en todo, pueda variar estas cosas el hortelano, a lo menos en parte, mediando la industria del injerir... Pero en las cosas artificiales, quedándose en pie lo principal, que es la sustancia, cada día varía el uso, el modo y lo accesorio... Pues si "en lo artificial", cuyo ser consiste sólo en la mudable imposición de los hombres, puede el uso mudar en los trajes y oficios hasta la sustancia, y "en lo natural" se producen, por medio de los injertos, cada día diferentes frutos, ¿qué mucho que la comedia, a imitación de entrambas cosas, varíe las leyes de sus antepasados, e injiera industriosamente lo trágico con lo cómico, sacando una mezcla apacible destos dos encontrados poemas? 16

La imagen del hortelano no es original: la emplea ya Guarini (1588) en su defensa del Pastor Fido (véase Weinberg, p. 1079). Pero lo notable es que Tirso abandona las reservas del italiano y defiende al poeta-artífice que, reconciliando los "encontrados" elementos de una naturaleza variadísima, transforma la realidad e inventa otra naturaleza. Esta concepción del arte es análoga a la de Góngora: "Si tuvo exemplo en los pasados, ¿quién le pondrá culpa [a Góngora] por haber seguido sus huellas? Si no lo tuvo, tanto es más esclarecida su gloria quanta es la distancia de ser imitador a ser Artífice"17; y anuncia la poética de Gracián: "Es el arte complemento de la naturaleza y un otro segundo ser, que por extremo la hermosea y aun pretende excederla en sus obras. Préciase de haber añadido un otro mundo artificial al primero; suple de ordinario los descuidos de la naturaleza, perfeccionándola en todo: que sin este socorro del artificio, quedara inculta

16 El vergonzoso en palacio, Madrid, $195^{8}$, pp. 144-145.

17 Vázouez Siruela, Discurso sobre el estilo de don Luis de Góngora, en ArTigas, pp. $391-392$. 
y grosera". Dios dio el mundo al hombre, añade Gracián, "para que lo cultivase..., que con el arte lo aliñase y puliese. De suerte que es el artificio gala de lo natural, realce de su llaneza; obra siempre milagros" 18

Una visión tan poco admirativa de la naturaleza - "inculta", "grosera", "llana"- engrandece al poeta, que ya no necesita ser divinamente inspirado para revelar los secretos de un mundo imperfecto, sino que él mismo obra "milagros". El poeta es el creador que con su fiat "socorre" a la naturaleza, la mejora y la embellece. La inspiración va cediendo al artificio, la idea del poeta-profeta a la del poeta-artífice. Pero el conflicto entre estos dos conceptos no había podido resolverse en los días de Góngora. Amigos y enemigos del poeta invocan todavía al poeta-profeta para explicar o condenar la arquitectura grandiosa del Polifemo y de las Soledades. Vázquez Siruela alega que los arrebatos son propios de espíritus heroicos como el de Homero, Virgilio y Góngora (op. cit., p. 382). Pedro de Córdoba razona que la oscuridad era la manera con que los sacerdotes paganos solían esconder sus misterios del vulgo, y que, por tanto, la oscuridad de Góngora no es condenable ${ }^{19}$. Jáuregui ataca la vaciedad de la poesía gongorina con una evocación del verdadero poeta inspirado: "este ardor o este arrobo tan alto compete a los grandes poetas... mas debe... conseguir buen efeto destos ardimientos y raptos; emplearlos, digo, principalmente en concetos sublimes y arcanos... no en lo inferior y vacío de las palabras" (op. cit., p. 224). Con todo, la poesía pierde el aura de misterio que le confería la creencia en una inspiración divina. El mismo Jáuregui observa que el lector ya no necesita ser poeta para presumir de entender un poema culto, porque no se lee con "el temor y sumisión que otro tiempo" (p. 253). Hecho lamentable, según Jáuregui. De ahí la ironía con que critica los "arrobamientos" falsos de los nuevos poetas, su confianza en el solo ingenio y la sola imaginación, que llevan a la nada. En este debate, donde salta a la vista la empeñosa voluntad de defender la concepción renacentista del poetaprofeta, el "Lunarejo" es el único en contestar el cargo según los principios gongorinos: el descubrimiento de Góngora es haber comprendido la diferencia esencial entre el arte sagrado y el arte secular. Góngora, el Colón de la poesía, no su Mahoma, supo divorciar la función del poeta de la del profeta. A éste le incumbe esconder secretos y misterios grandes bajo un estilo llano, mientras a aquél le toca inventar "perfiles de donaire", poesía "toda adorno de dicciones, toda poma de palabras, toda aliño de elocuencias", espléndidamente "vana, hueca, vacía y sin corazón de misterio alguno"

Así, pues, España (160o: Lope, Tirso, Góngora) parecería situarse cronológicamente entre la polémica italiana y la querelle francesa. Sólo que todas esas declaraciones, en que entra tanto la afirmación del gusto

18 El Criticón, en Obras completas, ed. cit., p. $5^{87}$.

19 Examen del Antidoto, en ArTlgas, pp. $421-424$.

20 JuAn de Esplíosa Medrano, Apologético en favor de don Luis de Góngora, reimpreso en $E l$ apogeo de la literatura peruana colonial, Paris, 1938, p. 80. 
español, se insertan en una tradición nacional de libertad frente a las preceptivas clásicas ${ }^{21}$.

Brandeis University.

ANDrée Collard

\section{LA IMPRENTA EN QUE SE EDITÓ LA RECOPILACIÓN EN METRO DE DIEGO SANCHEZ DE BADAJOZ}

Entre los pliegos sueltos de la colección del Marqués de Morbecq, recientemente publicados por don Antonio Rodríguez-Moñino ${ }^{1}$, hay uno (el núm. xI) intitulado Relación muy verdadera de las rebelliones que ha auido en el Reyno de Inglaterra en el principio desta quaresma... Trata un tema de actualidad y es, como dice Rodríguez-Moñino, "buena muestra de la propaganda que se hacía entre el pueblo español a favor de Inglaterra en 1554". Además de carecer de todo valor literario, está incompleto. Pero tiene el mérito de aclararnos, en forma definitiva, un enigma que parecía insoluble: la imprenta en que se hizo la Recopilación en metro del bachiller Diego Sánchez de Badajoz. El colofón de esta última obra nos hacía saber únicamente que se había impreso "en la muy noble y leal ciudad de Seuilla junto al meson de la castaña.../a ocho dias del mes de Otu/bre Año de mil quini/entos y cincuenta/ y cuatro"2. Y he aquí cómo reza el colofón de la Relación muy verdadera: "En Seuilla por Juan canalla junto al me/son de la castaña: en xxiiij. dias de Março de mil/ quinientos y cincuenta y quatro". La imprenta de la Recopilación, que trabajaba el mismo año junto al mismo mesón, es sin duda la de Juan Canalla.

Ni los historiadores de la imprenta de Sevilla ni los estudiosos de la obra de Sánchez de Badajoz habían conseguido determinar el nombre del impresor de este volumen. Francisco Escudero y Perosso, que en su Tipografia hispalense (Madrid, 1894) indica, para los siglos xVI y xVII, la situación dentro de la ciudad de todas o la gran mayoría de las imprentas sevillanas, no menciona el "Mesón de la Castaña" y dice de Juan Canalla que vivía en la "collación de San Juan de la Palma”, o sea que lo sitúa por la parroquia en que se hallaba su casa impresora. Joaquín Hazañas y La Rúa, La imprenta en Sevilla (Sevilla, ${ }_{1892)}$, indica que el mesón se hallaba frontero a las "Siete Revueltas", lugar en que se establecieron muchos impresores sevillanos en el siglo xvi, y agrega que "no es fácil decir a cuál de ellos pueda

21 Nota adicional: Después de escrito el presente trabajo, veo el artículo de Emilio Carilla, "Antiguos y modernos en la literatura española", $A F$, núm. 4, pp. 195-216. Pero nos acercamos al tema de una manera distinta.

1 Los pliegos sueltos de la colección del Marqués de Morbecq (siglo xivi), ed. facs. y pról. de Antonio Rodríguez-Moñino, Madrid, 1962. (Véase mi reseña en las pp. $195^{-197}$ de este mismo número).

2 Si bien no es excepcional el colofón incompleto, es mucho más corriente la supresión total del pie de imprenta que su presentación parcial. 